\title{
APLIKASI KONSEP PERSONAL KNOWLEDGE MANAGEMENT (PKM) DENGAN SOCIAL WEB
}

\author{
Nuril Kusumawardhani Soeprapto Putri \\ Information Systems Department, School of Information Systems, Binus University \\ Jln. K.H. Syahdan No. 9, Palmerah, Jakarta Barat 11480 \\ nuril@binus.ac.id
}

\begin{abstract}
This study discusses the impact of social media to the development of personal knowledge management (PKM). Here the author describeS the factual condition of the company that useS social media as a means of personal knowledge management. Furthermore, these interaction patterns have significant impact on the organization. The purpose of this article is to analyze the application of personal knowledge management concept, combined with the social media concept that focuses on social networks with the consideration that they are widespreadly used by the public. Plus the emergence of social networking sites are increasingly new added value to the development of social media. The method used is literature study obtained from the online journals, articles and text books. The result of this study is expected to expand the use of social networking as a means of personal knowledge management in the organization.
\end{abstract}

Keywords: personal knowledge management (PKM), social media, social networking

\begin{abstract}
ABSTRAK
Kajian ini membahas dampak perkembangan social media terhadap personal knowledge management (PKM). Di sini penulis memaparkan kondisi faktual perusahaan yang memanfaatkan social media sebagai sarana personal knowledge management. Lebih jauh lagi, pola berinteraksi tersebut membawa dampak signifikan terhadap organisasi. Tujuan dari penulisan ini adalah untuk menganalisis penerapan konsep personal knowledge management yang dipadukan dengan konsep social media yang dititikberatkan pada jejaring sosial dengan pertimbangan bahwa penggunannya semakin marak dipergunakan oleh masyarakat. Ditambah lagi bermunculannya situs-situs jejaring sosial baru semakin meningkatkan nilai tambah bagi perkembangan social media. Metode penelitian yang digunakan adalah studi literatur, yang diperoleh dari online journal, artikel dan text book. Hasil dari kegiatan ini diharapkan akan memperluas penggunaan jejaring sosial sebagai sarana PKM dalam organisasi.
\end{abstract}

Kata kunci: personal knowledge management (PKM), social media, jejaring sosial 


\section{PENDAHULUAN}

Kita sadari ataupun tidak, setiap individu memiliki pengalaman, pendidikan, kisah hidup atau kenangan yang tidak pernah diceritakan kepada orang lain dan disimpan untuk diri sendiri. Berbagai macam judul buku yang kita beli sehingga memenuhi isi lemari buku kita, berkas-berkas ataupun catatan kecil yang tidak sengaja masih tersimpan, kartu ucapan dari orang terdekat, foto-foto bersama kerabat dan teman-teman kita, buku catatan semasa duduk dibangku sekolah, materi-materi seminar dan berbagai pelatihan yang pernah kita ikuti, berbagai macam CD software yang tidak terinstal di komputer kita, serta daftar nama dan alamat dari orang-orang yang kita kenal, keseluruhan tersebut merupakan sesuatu yang kita miliki dan sebagian besar tidak pernah kita sentuh lagi.

"We know far more than we remember", kita mengetahui jauh lebih banyak daripada apa yang kita ingat. Kita memiliki teman dari berbagai macam latar belakang, dan tanpa kita sadari kita mempelajari berbagai macam hal dari orang yang ada di sekitar kita. Misalnya, jika kita memiliki seorang teman yang berprofesi sebagai seorang dokter, maka kita dapat mengetahui berberapa jenis penyakit dan cara pengobatannya, melalui berbagai perbincangan dengan dia. Jika teman kita adalah seorang pakar investasi, tanpa kita sadari kita telah mengambil kursus singkat mengenai investasi melalui perbincangan informal disela rutinitas sehari hari.

Maka bagaimanakah kita menggunakan berbagai macam sumber daya yang telah kita dapatkan, dengan atau tanpa kita sadari tersebut secara efektif? Padahal kita sendiri sering kali tidak menyadari bahwa kita memiliki sumber daya tersebut. Maka disinilah peranan Personal Knowledge Management agar kita dapat mengetahui pengetahuan apa sajakah yang kita miliki dalam konteks individual, dan bagaimana cara kita mengaturnya serta menggunakannya untuk mencapai target yang kita inginkan, sehingga kita dapat terus-menerus menciptakan pengetahuan baru.

Perkembangan Social Web menunjang keberhasilan dari Personal Knowledge Management (PKM). Situs Facebook, Youtube, Linkedin, Friendster, Twitter dan lain sebagainya, merupakan sarana penyimpanan dan pertukaran informasi dan pengetahuan secara informal. Melalui jejaring sosial kita dapat terhubung dengan individu-individu dari berbagai latar belakang baik yang sudah kita kenal dalam dunia nyata maupun yang hanya kita kenal dalam dunia maya. Pertukaran informasi dan pengetahuan antar individu dapat lebih teroganisir dan tersimpan dengan baik. Hal ini diharapkan dapat membantu individu untuk mengelola sumber daya yang dimilikinya, sehingga dapat menstimulasi timbulnya penciptaan pengetahuan baru.

Keberhasilan penerapan PKM dengan menggunakan media Social Web dalam level individu tersebut menstimulasi tantangan yang lain. Bagaimanakah konsep tersebut dapat diterapkan dalam level organisasi? Cara apakah yang dapat digunakan bagi pihak organisasi atau perusahaan untuk memfasilitasi pertukaran pengetahuan personal tersebut, sehingga dapat digunakan dalam level organisasi?

Kajian ini akan membahas mengenai pengaplikasian konsep Personal Knowledge Management secara mendalam dengan menggunakan social web dalam ruang lingkup organisasi. Penulis memfokuskan pada penggunaan jejaring sosialsebagai salah satu aplikasi dalam social web. Diakhir bagian, dipaparkan mengenai studi kasus salah satu organisasi yang menerapkan konsep Personal Knowledge Management melalui aplikasi internal social networking.

\section{Personal Knowledge Management (PKM)}

Menurut Razmerita et al. (2008) , Knowledge Management memfokuskan pada proses pengelolaan pengetahuan organisasi, sedangkan Personal Knowledge Management (PKM) 
menitikberatkan pada petualangan individu dalam melakukan pembelajaran, efisiensi dalam bekerja atau dalam hal sosialisasi antar individu. Martin (2008) dalam tulisan Cheong \& Tsui (2010) memaparkan bahwa, PKM adalah mengetahui pengetahuan apa saja yang kita punya dan bagaimana cara kita mengelolanya, memobilisasi dan menggunakannya untuk mencapai target yang kita inginkan dan bagaimana cara kita untuk menciptakan pengetahuan secara terus-menerus. PKM merupakan kumpulan dari keahlian yang diperlukan untuk memecahkan permasalahan, pengambilan keputusan dan pekerjaan pengetahuan lainnya, serta menyoroti arti pelaksanaan dari setiap keterampilan dan pentingnya integrasi teknologi (Avery et al., 2001).

Kumpulan dari keterampilan tersebut, dirangkum Dorsey (2000) dalam Agnihotri \& Troutt (2008) ke dalam tujuh keterampilan PKM (PKM Skills), yaitu: (1) pengambilan informasi merupakan keterampilan yang digunakan untuk mengelola proses pencarian individu (contoh: pelebaran atau penyimpatan pencarian), Boolean logic dan aplikasi pengulangan pencarian; (2) pengevaluasian informasi. Dengan tujuan untuk menemukan informasi yang berharga dan relevan, maka PKM mengehendaki evaluasi dari informasi yang tersedia secara luas, yang tidak disaring ataupun disensor; (3) pengaturan informasi - pengaturan dari informasi (contoh: kronologikal, fungsional, role-based) memfasilitas KM dengan cara menghubungkan informasi baru dan lama; (3) analisis informasi - membangun keterampilan organisasi informasi dalam menganalisis dapat membantu pengguna untuk mengubah informasi menjadi pengetahuan; (4) penyajian informasi keterampilan PKM melibatkan penyajian informasi kepada pihak lain, melalui desain yang efektif dan komunikasi; (5) pengamanan informasi - dengan adanya pertumbuhan resiko dan kesempatan yang terasosiasi dengan information sharing, para knowledge worker harus dapat menjamin keamanannya; (6) pengkolaborasian di sekitar informasi - keterampilan PKM yang memungkinkan para knowledge worker untuk berpartisipasi dalam aktifitas yang bernilai tinggi (high-value activities) di dalam suatu proses kolaborasi di sekitar informasi.

Tujuan utama dari PKM adalah untuk menyediakan kerangka kerja bagi para knowledge worker agar dapat mengelola informasi baru, mengintegrasikannya dan memperkaya basis data pengetahuan pada masing-masing individu secara efektif. Jika hal ini berhasil dilakukan, dapat memberdayakan setiap individu untuk menerapkan pengetahuan personal milik mereka. Pengetahuan tersebut dapat digunakan untuk memecahkan berbagai permasalahan baru dan lama, selain itu mereka dapat belajar dari pengalaman yang baru serta menciptakan pengetahuan baru. PKM merupakan proses yang berkesinambungan dan interaktif dan tidak terlepas dari proses knowledge management lainnya (Cheong \& Tsui, 2010).

\section{Personal Knowledge Management (PKM) dalam Organisasi}

PKM seringkali dipandang sebagai perubahan kewajiban dalam personal learning, pertumbuhan dan knowledge sharing dari level organisasi ke level individual. Organisasi haruslah menyadari bahwa mereka tidak dapat mengendalikan keinginan individu untuk berkreasi, berinisiatif atau mengembangkan pengetahuan dan keahlian. Namun, organisasi harus membantu mengembangkan keinginan individu untuk memperoleh karakteristik tersebut (kreatif, insiatif dan pengembangan pengetahuan serta keahlian) (Jefferson, 2006).

Jefferson (2006) menyimpulkan bahwa, manfaat dari PKM tidak hanya dirasakan bagi para individual. Dengan menggabungkan individual style dan preferensi ke dalam KM tradisional, produktifitas organisasi dapat ditingkatkan tanpa memaksakan para knowledge worker. Tradisional KM memfokuskan pada peningkatan efektifitas suatu organisasi, PKM lebih ke arah peningkatan individu. Namun, sejalan dengan tercapainya efektifitas dari individu, secara langsung dapat meningkatkan kolaborasi antar individu, yang dapat mempengaruhi tingkat efektifitas suatu perusahaan atau organisasi. 


\section{Web 2.0 atau Social Web Tools}

Beberapa tahun belakangan ini, kita telah menjadi saksi mata transformasi web dari web statis kearah "living web" atau dikenal dengan era Web 2.0. Istilah "living web" digunakan untuk menggambarkan pengguna yang diberikan keutamaan untuk dapat menentukan konten, berkolaborasi dan berbagi pengetahuan. Berbagai macam tools yang terdapat pada Web 2.0 adalah blogs, wikis, tags, RSS feeds, social bookmarking tools dan AJAX. Dengan menggunakan Web 2.0 tools, seseorang tidak secara pasif mengkonsumsi informasi. Namun, mereka berkontribusi secara aktif, bahkan mengkustomisasi tools dan teknologi yang ingin mereka gunakan. Web 2.0 memfasilitasi jejaring sosialdan kolaborasi, sehingga dinamakan juga dengan Social Web (Razmerita et al, 2008).

Web 2.0 memperkenalkan tools komunikasi baru, yang dapat meningkatkan kolaborasi knowledge worker dan pendistribusian pengetahuan. "Wikis , blogs, group-messaging software dan fitur 'like', dapat membuat intranet perusahaan kedalam suatu pembangunan struktur perubahan dengan cara distribusi, autonomous peers - suatu platform kolaborasi yang merefleksikan bagaimana penyelesaian suatu pekerjaan” (McAffee, 2006, p. 21 di Razmerita et al., 2008). Tidak seperti tradisional KM tools yang memfokuskan pada proses penangkapan pengetahuan (knowledge capture). Teknologi baru ini memfokuskan pada pengembangan knowledge work dengan cara memfasilitasi kolaborasi. Selain itu, Web 2.0 tools tidak mahal dan sangat mudah digunakan.

Menurut O’Reilly (2005), Web 2.0 atau Social Web telah memperkenalkan konsep baru dan tools yang dapat digunakan untuk mengoperasionalkan suatu visi yang lebih kearah socialcentric. Sistem online jejaring sosial (online social networking), seperti LinkedIn, Myspace dan Facebook memungkinkan bagi seseorang untuk melakukan interaksi dengan orang lain dalam skala yang cukup besar. Blogs, microblogs (contohnya, Twitter) dan instant messaging tools (contoh: Skype), telah menyediakan alat komunikasi baru untuk berinteraksi dengan orang lain secara efektif dalam komunitas terbuka. Selain itu, tools jenis baru yang bersifat radikal telah muncul, seperti Wikis (Wikipedia) dan social bookmarking (Delicious), yang bertujuan secara langsung untuk mendukung PKM dan mendorong collective intelligence.

\section{Social Networking}

Boyd dan Ellison (2007) mendefinisikan situs jejaring sosial (social network sites) sebagai layanan berbasis web yang memperbolehkan para individu untuk: (1) membangun sebuah profil publik dan semi-publik dalam suatu sistem yang memiliki batasan-batasan, (2) memiliki suatu daftar yang berisikan pengguna-pengguna lain yang tersambung dengan individu tersebut, (3) dapat melihat dan melintasi daftar koneksi-koneksi yang terhubung dari para individu lainnya dalam sistem tersebut. Keunikan dari situs ini bukan pada kemampuan yang memperbolehkan para individu untuk bertemu dengan individu lain yang tidak dikenalnya dalam dunia nyata, namun pada kemampuan untuk mengartikulasikan dan membuat situs pribadi mereka dapat dilihat oleh individu lain.

Dari definisi tersebut diatas dapat disimpulkan bahwa, berbagai macam jejaring sosial online (LinkedIn, Myspace dan Facebook), blogs dan microblogging (Blogger, Twitter), video atau photo sharing (Youtube, Flickr), instant messaging dan masih banyak lainnya yang terdapat pada gambar 1.0, dapat dikategorikan sebagai jejaring sosial (Gambar 1). Hal ini dikarenakan, keseluruhan situs tersebut memiliki tiga kemampuan yang dipaparkan oleh Boyd dan Ellison (2007). Contohnya pada aplikasi Blogger. Disini pengguna tidak hanya difasilitasi untuk menulis jurnal pribadi yang tersimpan dalam archive, tapi juga dapat menjadi pengikut (follower) bagi blogger lainnya atau bahkan memiliki pengikut sendiri. Hal ini memungkinkan bagi pengguna untuk membentuk komunitas tersendiri yang memiliki minat serupa. 
Beberapa aplikasi tersebut dapat terintegrasi satu sama lain. Sehingga, kolaborasi yang dihasilkan antar pengguna didalamnya akan semakin kompleks. Contohnya, pengguna dapat mengintegrasi Yahoo Messenger, Facebook bahkan My Space ke dalam situs blog miliknya. Jika sudah terintegrasi, para blogger tersebut dapat menampilkan artikel yang dibacanya atau yang ditulisnya ke dalam akun Facebook sehingga dapat dibaca oleh lebih banyak pengguna.

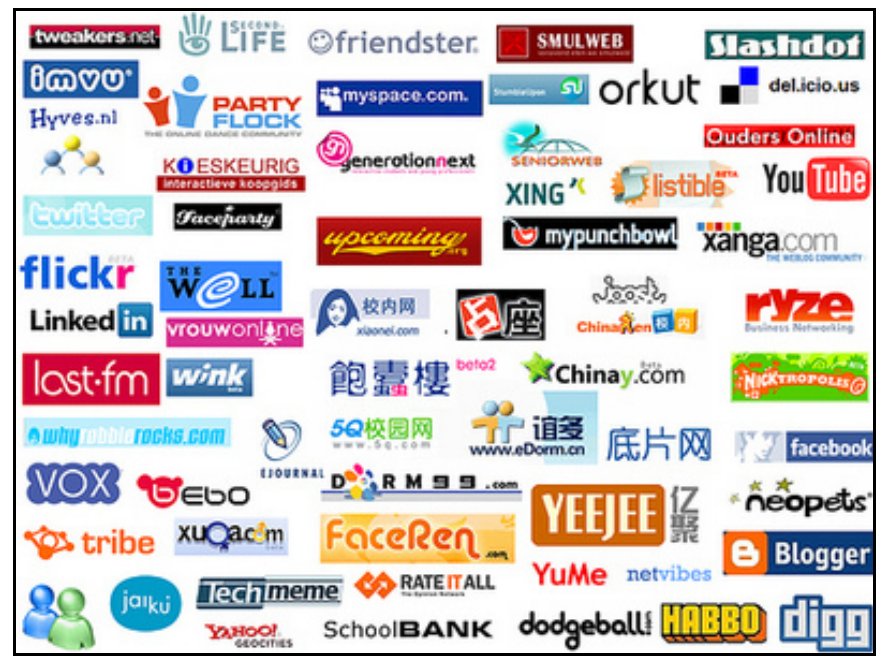

Gambar 1. Kumpulan jejaring sosial.

Pada saat seorang pengguna mendaftar ke salah satu situs jejaring sosial, ia akan diarahkan untuk mengidentifikasi individu lain dalam sistem tersebut, yang memiliki hubungan. Sebagian besar pengguna jejaring sosialtersebut belum tentu memiliki niat untuk "menjaring” atau berkenalan dengan orang-orang baru. Mereka lebih sering berkomunikasi dengan para individu yang berada pada jaringan mereka dan satu atau dua level dari extended social network.

Tahapan selanjutnya, pengguna dapat menikmati fasilitas yang ditawarkan oleh situs-situs tersebut. Youtube menawarkan layanan video sharing yang dapat diunduh dengan menggunakan tools yang disediakan secara cuma-cuma. Friendster, Myspace dan Facebook, menawarkan layanan yang lebih kompleks untuk memanjakan pengguna. Fitur instant messaging, tagging, photo \& video sharing, status update hingga layanan game online, dapat dinikmati melalui situs-situs tersebut. LinkedIn, lebih kearah profesional. Pengguna dapat terhubung dengan para profesional lain yang dalam berbagai bidang yang dikehendakinya. Profil pada LinkedIn, dapat juga berfungsi sebagai curriculum vitae pengguna. Foursquare memberikan fasilitas untuk menginformasikan lokasi keberadaan pengguna. Selain itu, pengguna dapat memberikan tips dan trik mengenai lokasi yang dikunjungi tersebut, sehingga dapat menjadi informasi bagi pengguna lain yang berkunjung.

Aplikasi jejaring sosialseperti Facebook, Myspace, LinkedIn, Foursquare, telah berhasil mengumpulkan komunitas pengguna dalam jumlah yang cukup besar. Seperti yang terlihat pada Fambar 2, pengguna Facebook mengalami kenaikan sebesar 71\% dari tahun 2009 ke tahun 2010. Hal ini juga dialami oleh aplikasi jejaring sosial lainnya (Social Media Influence, 2011). Di luar dari dimensi sosial, jejaring sosial telah membuka jalan bagi perkembangan pembelajaran secara informal. Breslin (2008) dalam Razmerita et al (2009) memperkirakan bahwa 75-80 persen dari pembelajaran dilakukan secara informal dan sekitar 40-50 persen dari total keseluruhan karyawan, mengakses informasi dan pengetahuan melalui situs media sosial. Proses pembelajaran secara informal ini, terbantukan dengan adanya fitur pertukaran (exchange fitur). Fitur pertukaran kontak bisnis, musik, foto, video bahkan penujuk halaman buku (bookmark), merupakan kunci keberhasilan dari social networking. 


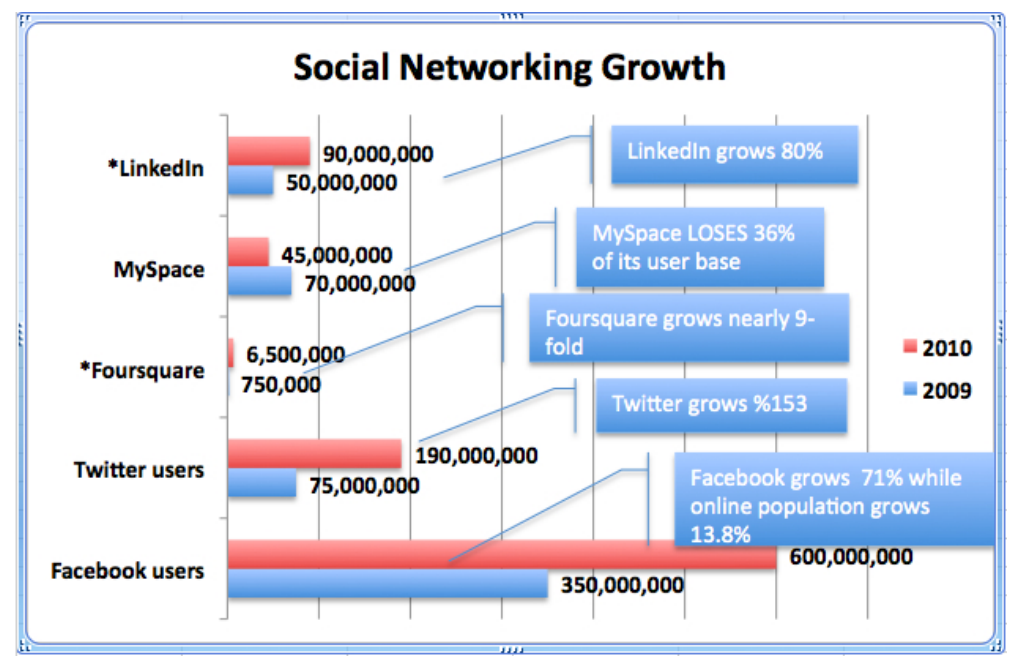

Gambar 2. Pertumbuhan jejaring sosial (Sumber: Social Media Influence, 2011)

\section{Personal Knowledge Management Tools dalam Social Web}

Dalam konteks PKM, para individu memiliki keahlian yang berbeda-beda. Sehingga, mereka membutuhkan tools yang bermacam-macam. Pemanfaatan tools yang optimal sangatlah bergantung pada performa para knowledge worker dan pengguna lainnya dalam mengasimilasi keahlian PKM dan teknologi ke dalam perilaku KM. Para knowledge worker diharapkan untuk membuat keputusan dan melakukan pekerjaan yang berasosiasi pada pengetahuan, yang berdampak positif terhadap kinerja perusahaan serta terhadap diri mereka sendiri. Oleh karena itu, tools dari PKM harus sejajar dengan keahlian khusus serta PKM yang dipilihnya. Hal ini untuk membantu para pengguna dalam melakukan berbagai knowledge activites (Agnihotri \& Troutt, 2008). Berdasarkan survei yang dilakukan oleh Razmerita et al. (2008) terhadap tools Web 2.0 yang ada saat ini, tools PKM dapat dibagi menjadi enam kategori sebagai berikut:

\section{Personalised Webpages}

Fitur ini memungkinkan bagi pengguna untuk mengubah tampilan situsnya. Pengguna dapat memilih warna, wallpaper serta memilih aplikasi mini yang diinginkan (contohnya: kalender, alarm, translator, dll.). Beberapa situs jejaring sosial yang dapat dipersonalisasikan adalah Page Flake, Newsgator, iGoogle (Gambar 3), My Yahoo dan Live.com. Bahkan Facebook, sebagai situs jejaring sosial terpopuler, menambahkan fitur ini pada layanan terbarunya.

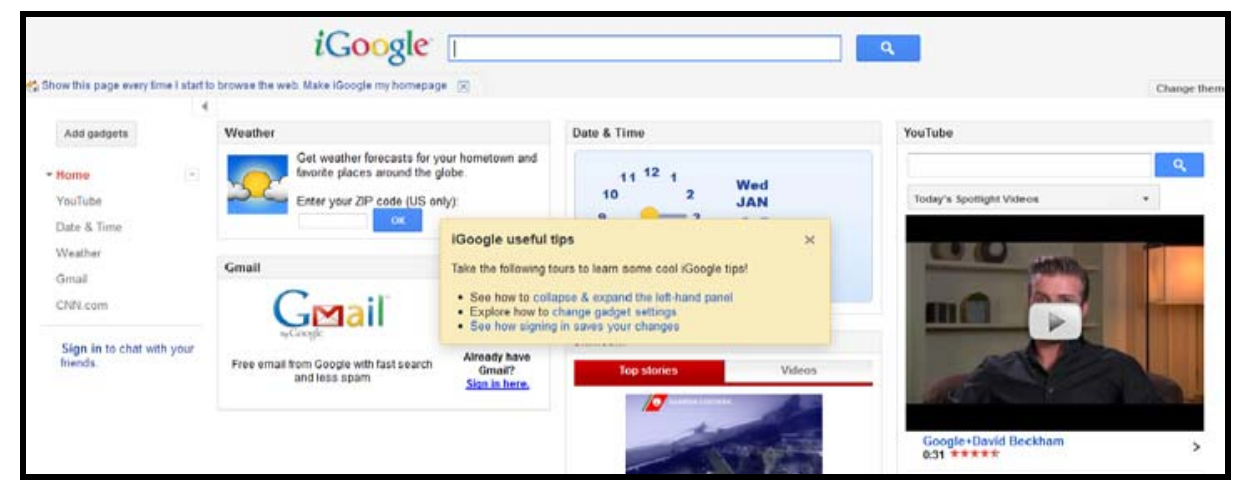

Gambar 3. iGoogle (Sumber: Google Inc, 2012). 


\section{Personalised Search Tools}

Tools ini menyediakan sarana untuk mengambil (retrieving) dan membagi informasi. Swicki (www.eurekster.com) merupakan portal pencarian yang dapat dipersonalisasikan, pada topik yang dipilih oleh suatu komunitas tertentu. Swicki (Gambar 4) akan memindai berbagai macam data yang diindeks di Yahoo Search, ditambah semua sumber tambahan yang telah ditentukan, kemudian menyajikan hasil pencarian tersebut ke dalam sebuah format yang terbaru dan dapat diluncurkan kedalam situs pribadi kita.

\section{Social Bookmarking}

Tools ini menyediakan cara sederhana bagi para individu dalam suatu komunitas untuk berbagi penunjuk halaman buku (bookmarks) dari berbagai sumber di internet. Heystacks (www.heystacks.com) merupakan salah satu alat yang menyediakan berbagai macam koleksi, pengklasifikasian dan pembagian hasil pencarian web. Hasil pencarian dapat ditambahkan kedalam salah satu daftar yang dimiliki oleh pengguna, dikenal dengan istilah 'stacks'. Namun daftar tersebut dapat digabungkan dan dimanfaatkan oleh pengguna lainnya. Daftar dapat diatur untuk pribadi maupun umum, serta dapat dibagikan kepada para pengguna lainnya yang termasuk kedalam daftar teman kita. Dengan menggunakan Heystacks (Gambar 5), pengelolaan dari bookmarks menjadi aktifitas sosial. Sayangnya, tools ini hanya dapat digunakan bagi para pengguna Ipad dan Android.

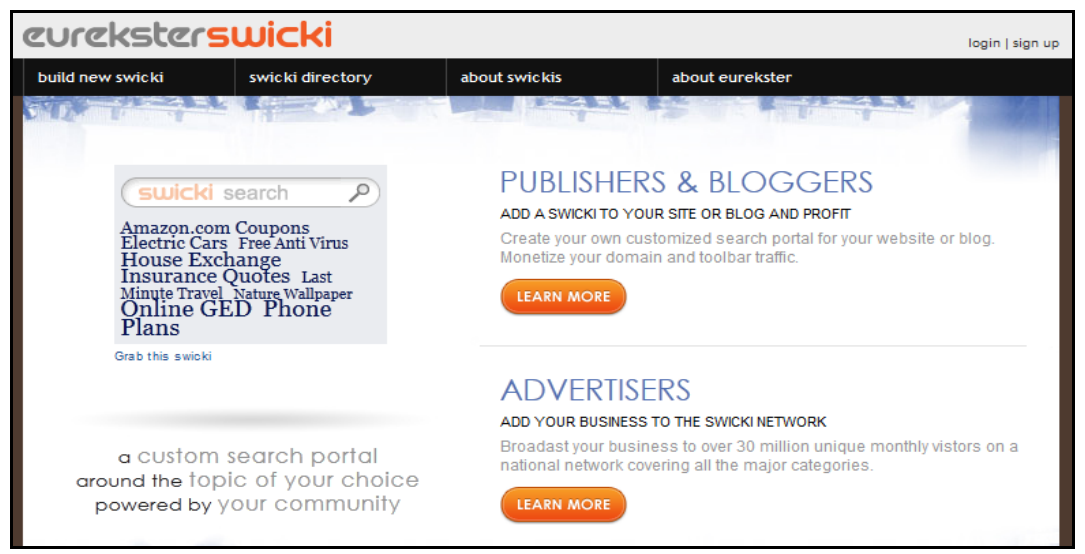

Gambar 4. Swicki (Sumber: Eurekster, 2012)

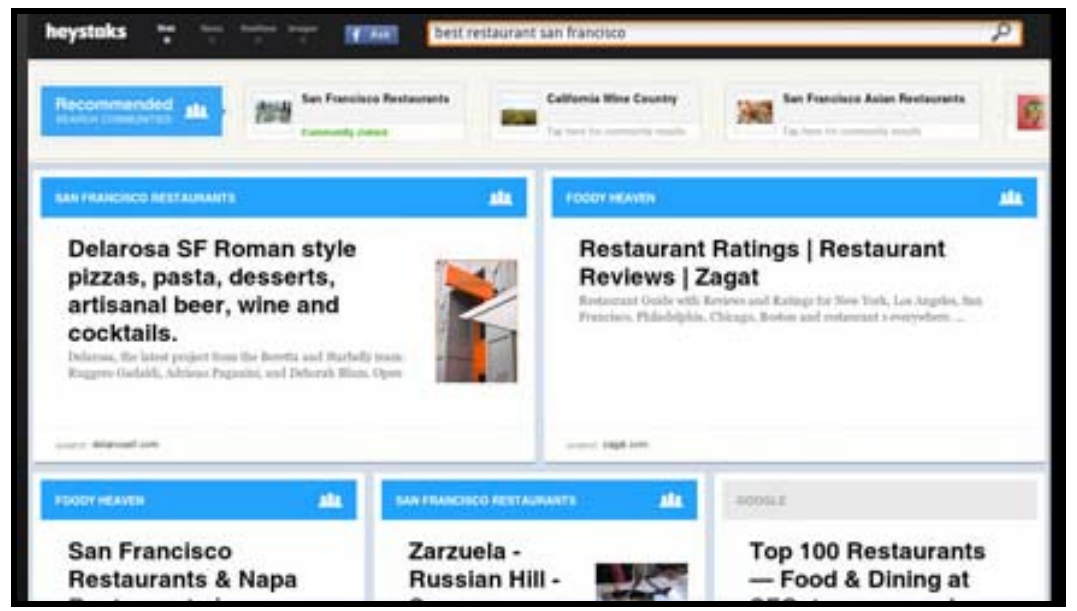

Gambar 5. Heystacks (Sumber: Heystacks, 2012) 


\section{Personalised Live Discussion Forum}

Tools ini dapat membantu dalam menganalisis, mengevaluasi, menyajikan dan berbagi informasi. Contohnya melalui Tangler (www.tangler.com). Tangler (Gambar 6), memungkinkan bagi para pengguna untuk menciptakan forum diskusi secara langsung dan untuk berbagi diskusi dengan lainnya. Tidak seperti sarana forum terbuka (Kaskus dan lainnya), tools ini dapat memiliki forum pribadi yang hanya dapat diakses bagi komunitas yang kita miliki.

\section{Virtual Worlds}

Tools ini dapat mendorong para individu untuk berbagi informasi. Secondlife (www.secondlife.com) atau Vastpark (www.vastpark.com) merupakan plaftorm 3D yang memungkinkan penggunanya untuk menciptakan dunia virtual yang dapat mereka miliki dan mereka bagi dengan yang lainnya. Tools ini juga dapat digunakan sebagai 3D gaming, membuat sebuah presentasi 3D atau menciptakan jejaring sosial dimana para pengguna dapat berkomunikasi, bekerja sama, belajar dan berkolaborasi.

\section{Blogs dan Wikis}

Kedua tools tersebut dapat membantu dalam proses pengeditan, penyajian dan pengorganisasian informasi atau pengetahuan oleh para individu atau dalam pengkolaborasian dengan individu lainnya. Kategori khusus dalam Wikis adalah Wikis Personal yang dapat memungkinkan para individu untuk mengelola informasi didalam desktop atau peralatan mobile computing, dengan cara yang serupa dengan Wikis yang normal. Contoh dari wiki personal adalah Pimki (pimki.rubyforge.org), di dalamnya terdapat mindmaps, fungsi pencarian dan to-do list.

\section{Beehive: IBM Internal Social Networking}

Beehive (Gambar 7) adalah situs jejaring sosial internal yang memberikan para IBMers (julukan bagi karyawan IBM), sebuah "rich connection to the people they work with", dalam level personal dan profesional. Beehive membantu para karyawan terutama karyawan baru untuk membangun koneksi, melacak teman-teman dan rekan kerja, serta memperbarui kontak dengan orangorang yang telah bekerja di IBM pada waktu yang lampau. Seperti halnya situs jejaring sosial Facebook, pengguna Beehive dapat membuat profil, memposting foto, memposting update, memposting komentar, menyelenggarakan suatu acara bahkan menandai (tag) foto (Ward, 2012). Para karyawan dapat melihat foto terbaru dari para mantan rekan satu tim dimana mereka pernah bekerja sama.

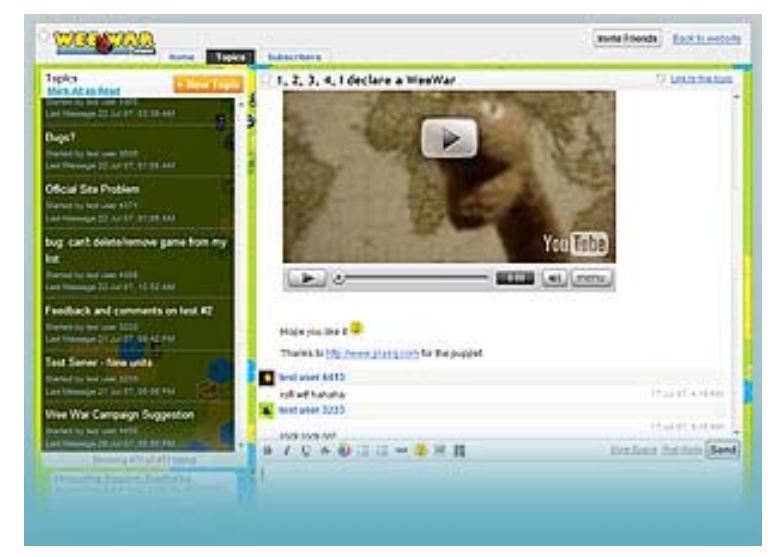

Gambar 6. Tangler (Sumber: Tangler, 2012) 


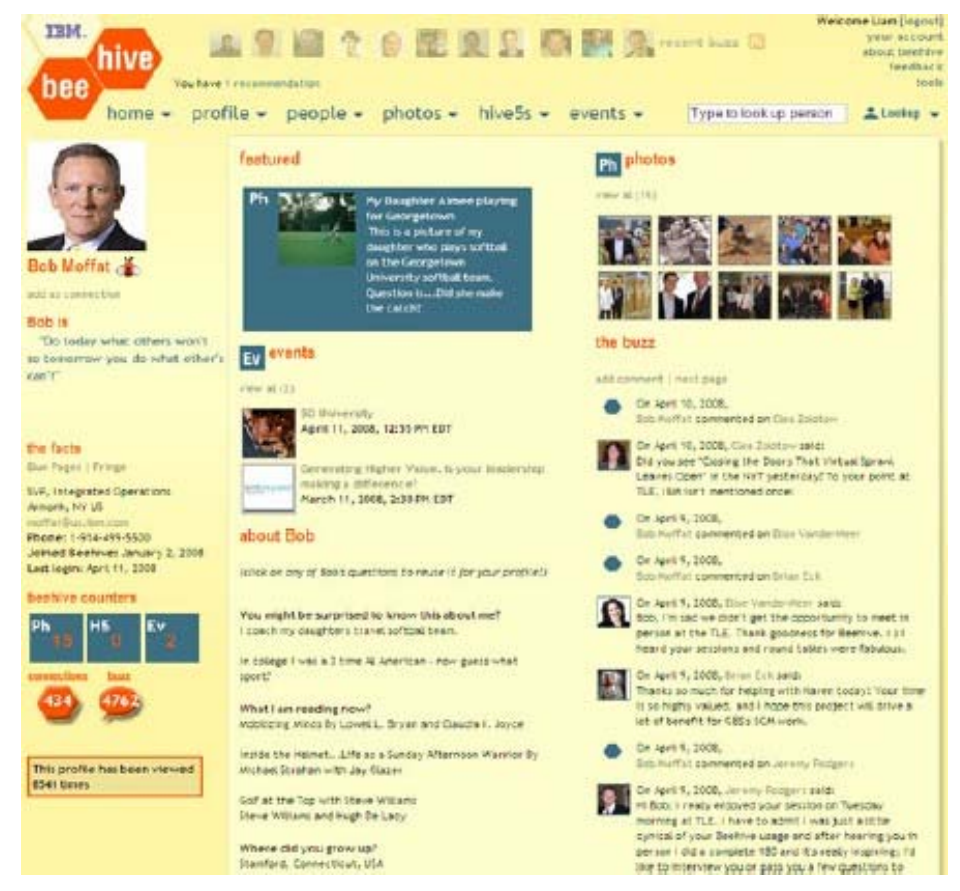

Gambar 7. Beehive (Sumber: Ward, 2012).

Pengguna Beehive dapat membuat daftar top-five dikenal dengan "hive fives", yang digunakan untuk berbagi pendapat terhadap berbagai topik yang mereka sukai. Contohnya, mereka dapat membuat daftar "hive five" yang berisikan ide-ide mereka tentang suatu proyek dann kemudian mengundang para anggota dari tim untuk menggunakan daftar tersebut serta mensuarakan opini mereka. Hive fives merupakan cara mudah untuk berbagi ide dan agar tetap berhubungan dengan para anggota tim.

Beehive juga dapat berguna untuk panggilan konferensi. Jika pengguna tidak tahu siapa saja yang akan diundang dalam suatu konferensi, mereka dapat mengakses profil melalui Beehive untuk mengetahui minat para karyawan, baik yang berhubungan dengan pekerjaan ataupun informal. Beehive merupakan cara cepat untuk mencari tahu mengenai seseorang dan apa yang mereka lakukan dalam keseharian.

IBM Research meluncurkan Beehive untuk mempelajari empat permasalahan yang berhubungan dengan social software dalam tempat kerja seperti yang terlihat pada Gambar 8. Ternyata, hasil riset yang ditemukan amat mengejutkan para eksekutif perusahaan, yaitu: (1) para karyawan menggunakan jejaring sosial internal, agar dapat mengenali rekan kerjanya dengan lebih baik pada level personal dan untuk mengecek orang-orang baru; (2) para karyawan menggunakan Beehive agar dapat terhubung dengan orang-orang yang tidak mereka kenal. Dalam situs publik seperti Facebook, para individu berhubungan dengan "teman” yang sudah mereka tahu ataupun yang sudah pernah mereka temui; (3) para karyawan menggunakan jejarin sosial internal untuk mengetahui tentang peluang karir; (4) para paryawan menggunakan jaringan tersebut untuk membuat orang lain tertarik terhadap ide-ide dan proyek mereka (Kreitzberg, 2012).

Alasan terjadinya keempat hal tersebut dikarenakan, internal social networking yang bersifat informal, mendorong para karyawan untuk secara leluasa mengenal satu sama lain serta menonjolkan kemampuan pribadinya. Seperti halnya Facebook yang bersifat 'sticky website', Beehive milik IBM memiliki layout yang menarik, interaktif dan user friendly. Nilai tambah yang dimiliki oleh internal social networking dibandingkan dengan jejaring sosial pada umumnya adalah para anggota yang 
terdaftar merupakan para kolega, anggota kelompok atau tim, mantan kolega, mantan tim dari satu perusahaan yang sama. Sehingga, akan lebih mudah bagi mereka untuk menemukan anggota lain yang memiliki minat dan hobi yang sama. Informasi dan pengetahuan yang ada di internal perusahaan dapat dibagikan secara informal serta didiskusikan oleh para pengguna, tanpa harus bertemu secara langsung. Mengingat IBM memiliki perwakilan di berbagai negara.

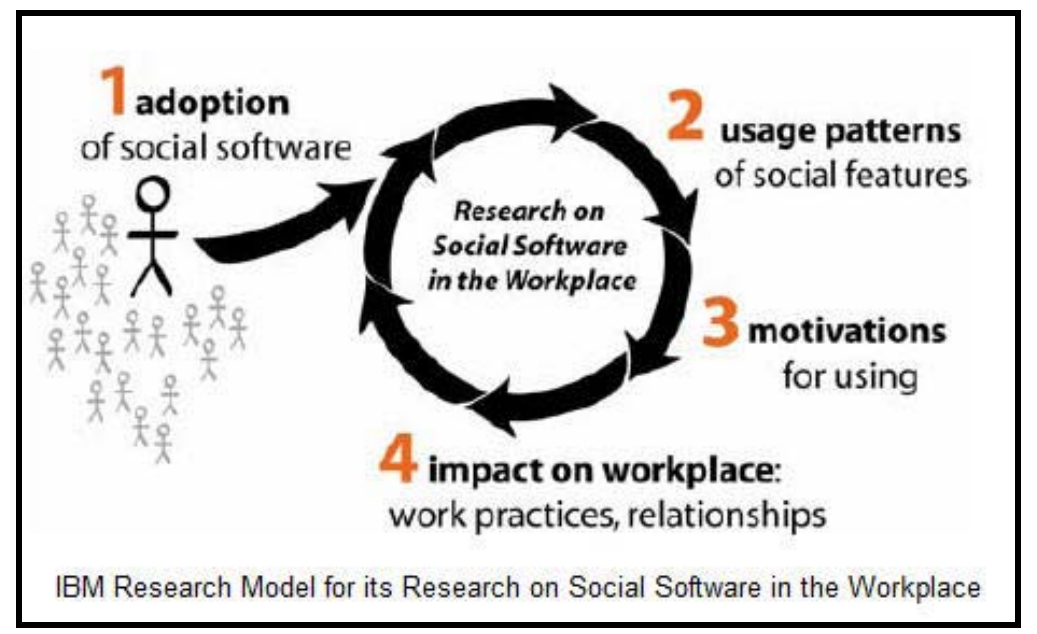

Gambar 8. Social Software dalam tempat kerja (sumber: Kreitzberg (2012).

Kemudian, apa sajakah manfaat yang dapat dirasakan oleh perusahaan melalui pengembangan situs jejaring sosial internal ini? Para peneliti dari IBM melaporkan bahwa para karyawan yang secara aktif terhubung dengan jaringan tersebut, memiliki kepedulian yang lebih dibandingkan dengan para karyawan yang pasif. Para karyawan tersebut memiliki keinginan lebih untuk berkontribusi terhadap perusahaan. Mereka juga berkeinginan untuk bertemu orang-orang baru dan melebarkan jaringan secara global (Kreizberg, 2012).

\section{PENUTUP}

Pentingnya pengelolaan individual knowledge, telah mendorong terbentuknya personal knowledge management (PKM). Manfaat PKM dirasakan tidak hanya bagi level personal saja, tapi juga organisasi. Ketika para individu dalam suatu organisasi menggunakan berbagai tools PKM, tanpa disadari kebiasaan untuk saling berbagi dan berkolaborasi antar individu, kelompok, komunitas hingga ke level organisasi mengalami peningkatan. Salah satu aplikasi yang menjadi fokus dalam kajian ini adalah aplikasi jejaring sosial. Popularitas penggunaan jejaring sosial di kalangan individu menarik minat suatu organisasi untuk mengembangkan suatu platform yang serupa. Beehive, aplikasi jejaring sosial internal buatan IBM telah menghasilkan manfaat yang signifikan, baik di level personal maupun level organisasi. Peningkatan kepedulian antar karyawan untuk berkontribusi lebih terhadap perusahaan, merupakan salah satu dampak yang dihasilkan dari pengembangan jejaring sosial internal. Hal ini juga mendorong peningkatan jaringan sosial personal milik para individu, yang secara langsung dapat menciptakan kolaborasi yang lebih baik.

Dengan memberikan sarana yang tepat bagi para karyawan untuk berbagi informasi dan pengetahuan secara internal, organisasi juga dapat memanfaatkan perputaran arus informasi dan pengetahuan tersebut menjadi pengetahuan organisasi. Inovasi-inovasi yang dihasilkan dari pengetahuan tersebut merupakan kunci keberhasilan suatu organisasi dalam era knowledge economy 
saat ini. Mengingat besarnya manfaat yang dapat dirasakan oleh suatu organisasi, melalui pengaplikasian personal knowledge management dengan menggunakan social web, organisasiorganisasi lain dapat mengadopsinya. Di tengah maraknya era social media, penerapan ini dirasakan sangat penting bagi kelangsungan organisasi. Jejaring sosial internal dapat menggantikan peranan jejaring sosial seperti Facebook, MySpace dan lainnya dalam lingkup organisasi.

Penelitian lebih lanjut mengenai social web tools lainnya, ataupun integrasi atau gabungan antar social web tools sebagai alat pendukung personal knowledge management, dapat dilakukan sebagai pembanding jejaring sosial internal milik IBM.

\section{DAFTAR PUSTAKA}

Agnihotri, R., \& Troutt, Marvin D. (2008), The Effective Use of Technology in Personal Knowledge Management. Online Information Review, 33(2).

Avery, S., Brooks, E., Brown, J., Dorsey, P., dan O’Conner, M. (2001), Personal Knowledge Management: Framework for Integration and Partnership. ASCUE 2001 Conference Proceedings, North Myrtle Beach, SC.

Boyd, Danah M. \& Ellison, Nicole B. (2007). Social Network Sites: Definition, History, and Scholarship. Journal of Computer-Mediated Communication, 13(1).

Cheong, Ricky K.F. \& Tsui, E. (2010), The Roles and Values of Personal Knowledge Management: an Exploratory Study. The Journal of Information and Knowledge Management Systems, 40(2).

Diakses dari http://socialmediainfluence.com/2011/02/24/the-train-wreck-that-is-murdochs-socialnetwork/.

Eurekster. (2012). Swicki Eurekster Frontpage. Diakses dari http://www.eurekster.com/.

Google Inc. (2012). iGoogle Frontpage. Diakses dari http://www.google.com/ig?hl=en.

Heystacks. (2012). Heystacks Frontpage. Diakses dari http://www.heystacks.com/. http://www.prescientdigital.com/articles/intranet-articles/beehive-builds-buzz-at-ibm/.

Jefferson, Theresa L. (2006). Taking It Personally: Personal Knowledge Management. The Journal of Information and Knowledge Management System, 36(1).

Kreitzberg, Anne P. (2009), IBM’s “Beehive” Social Network Creates More than Buzz”. Diakses dari http://www.leadersintheknow.com/leaders/2009/01/ibms-beehive-social-network-createsmore-than-buzz.html.

O’Reilly, T. (2005). What is Web 2.0? Design Patterns and Business Models for the Next Generation of Software. Diakses dari http://oreilly.com/web2/archive/what-is-web-20.html.

Pimki. (2012). About Pimki. Diakses dari http://pimki.rubyforge.org/.

Razmerita, L., Kirchner, K., dan Sudzina, F. (2003). Personal Knowledge Management: The Role of Web 2.0 Tools for Managing Knowledge at Individual and Organisational Levels. Journal of Online Information Review, 33 (6), 102-1039. 
Secondlife. (2012), What is Secondlife. Diakses dari http://secondlife.com/whatis/?lang=en-US.

Social Media Influence. (2009). The train wreck that is Murdoch's Social Network.

Tangler. (2012). Tangler Frontpage. Diakses dari http://www.tangler.com.

Vastpark. (2012). Vastpark Frontpage. Diakses dari http://www.vastpark.com/.

Ward, T. (2012). Beehive Builds Buzz at IBM. Diakses dari 